EGU2020-17722, updated on 18 Mar 2021

https://doi.org/10.5194/egusphere-egu2020-17722

EGU General Assembly 2020

(c) Author(s) 2021. This work is distributed under

the Creative Commons Attribution 4.0 License.

\title{
A geochemical approach to reconstructing sediment dynamic and thermohaline circulation in the western Mediterranean over the last deglaciation
}

\author{
Jose Manuel Mesa-Fernández ${ }^{1,2}$, Francisca Martínez-Ruiz ${ }^{1}$, Marta Rodrigo-Gámiziz and Francisco J. \\ Jiménez-Espejo ${ }^{1}$ \\ ${ }^{1}$ Instituto Andaluz de Ciencias de la Tierra (IACT-CSIC), Armilla, Spain \\ ${ }^{2}$ Departamento de Mineralogía y Petrología, Universidad de Granada, Granada, Spain \\ ${ }^{3}$ Departamento de Estratigrafía y Paleontología, Universidad de Granada, Granada, Spain
}

The westernmost Mediterranean basins is an exceptional and sensitive region for reconstructing past climate and oceanographic conditions. Geochemical signatures from diverse sediment records in the Alboran Sea and the Balearic basin, in particular, Ti/ca and Fe/Ca ratios, as proxies for the relative abundance of siliciclastic vs. carbonate fraction, have been investigated. These have also been compared with other previously studied records from the western Mediterranean and the Gulf of Cadiz to elucidate the mechanisms triggering the relative variations between the carbonate and siliciclastic fraction. The lithogenic fraction represents around $70 \%$ of the sediment in the Alboran basin, which mainly derived from riverine discharge and coastal erosion. Resuspension of fine sediment particles from the slope and the sea floor by bottom-water currents is a relevant process in these basin. The studied records are located between $850 \mathrm{~m}$ and $2400 \mathrm{~m}$ below the sea level, under the influence of the Western Mediterranean Deep Water (WMDW), which is restricted to a water depth below 500-600 $\mathrm{m}$ and to the Moroccan margin. This deep current is formed in the Gulf of Lion, when the superficial and intermediate waters sink by a density increase, and flow out the basin through the Gibraltar Strait, contributing to the Mediterranean Outflow Water (MOW) along with the Levantine Intermediate Water (LIW). The WMDW formation is enhanced during cold and arid periods. The comparison with other previously studied records, support important variations of the mechanisms triggering the relative contribution of carbonate and siliciclastic fractions during the last 20,000 yrs. The, Ti/Ca and Fe/Ca ratios increased during cold and arid periods, such as the Heinrich Event 1 (HE1) and the Younger Dryas (YD). These changes are more prominent in the Balearic basin and the eastern Alboran basin than in the western Alboran basin and the Gulf of Cadiz. Thus, we hypothesized that the increase in the $\mathrm{Ti} / \mathrm{Ca}$ and $\mathrm{Fe} / \mathrm{Ca}$ ratios is rather related to the enhanced WMDW production and more remobilization of fine siliciclastic sediments. 